\title{
Effect of PEEK Particles on Physiomechanical Behavior of Carbon/Epoxy Composite
}

\author{
Muhammad Muslim Rehman (D), Khubab Shaker 1 , and Yasir Nawab \\ Textile Composite Materials Research Group, National Center of Composite Materials, School of Engineering and Technology, \\ National Textile University, Faisalabad 37600, Pakistan \\ Correspondence should be addressed to Yasir Nawab; ynawab@ntu.edu.pk
}

Received 14 December 2021; Revised 28 January 2022; Accepted 8 February 2022; Published 24 February 2022

Academic Editor: Subrata Mondal

Copyright (C) 2022 Muhammad Muslim Rehman et al. This is an open access article distributed under the Creative Commons Attribution License, which permits unrestricted use, distribution, and reproduction in any medium, provided the original work is properly cited.

\begin{abstract}
The inherently brittle nature and the susceptibility to impact damage hinder the use of carbon/epoxy composite in some areas. In this study, poly ether ether ketone (PEEK) microparticles were incorporated to increase the resistance to delamination and interlaminar fracture toughness. A hand lay-up technique followed by compression molding was used to fabricate composite. The influence of PEEK particles was evaluated by tensile, flexural, short beam shear (SBS), compression, and Charpy impact test. The Barcol hardness, density, fiber volume fraction, and void content were also determined. According to the result, a maximum improvement in the tensile and flexural strength was observed for $2 \%$ incorporation of PEEK particles. However, there is downturn found in the flexural modulus. Moreover, a notable increment in the matrix-dominated properties (short beam shear, compression, and Charpy impact strength) was found with the addition of the PEEK particles.
\end{abstract}

\section{Introduction}

The research and development in the aerospace, automobile, wind-energy, and modern sports equipment industry are strongly influenced by the trend of lightweight materials, having outstanding mechanical properties and durability in a range of environments. Fiber reinforced polymeric composite (FRPC) materials typically often have high specific strength and modulus than traditional engineering materials. The choice to pick constituent materials and customize them to achieve desired properties and versatility of design to reduce parts count make composites very desirable to many industries [1, 2]. Following the invention of carbon fiber, carbon/epoxy composites have become popular as the replacement for metals where a combination of some unique characteristics like high strength and stiffness, low coefficient of thermal expansion, excellent stress, and corrosion resistance are desired while maintaining a low weight of the system leading to the better fuel economy and low carbon emission [3]. Apart from several benefits, relatively brittle nature, poor toughness, and low tolerance to crack initiation and growth due to the highly cross-linked structure of epoxy resin are major drawbacks of using carbon/ epoxy composite in engineering applications.

To subdue these disadvantages, many attempts have been made to increase the toughness of the epoxy matrix. Commonly, the toughness of epoxy resin is enhanced by the incorporation, up to a particular percentage of the micro-nanosized rigid fillers/particles such as nanosilica, glass beads, crystalline cellulose, core-shell particles, and graphene [4-11]. Increment in the toughness depends on the type of particles, particle size, dispersion, and the interfacial interaction with the matrix. Some drawbacks associated with high a percentage of fillers/particles content, like increased resin viscosity and poor dispersion, will deteriorate the mechanical properties of the composite material [12-18]. Another technique used to increase the toughness is the addition of miscible thermoplastic or thermoelastic materials in epoxy. Upon curing, these miscible materials become immiscible and form a second phase within the epoxy matrix. However, controlling the morphology, distribution, and the size of this reaction-induced second phase is a 


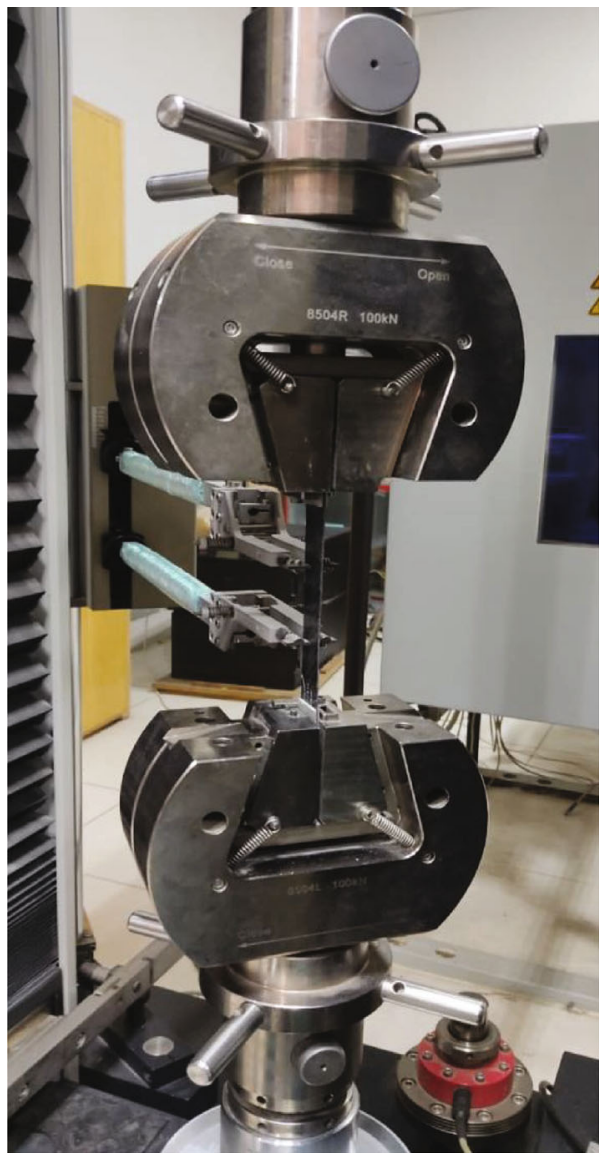

(a)

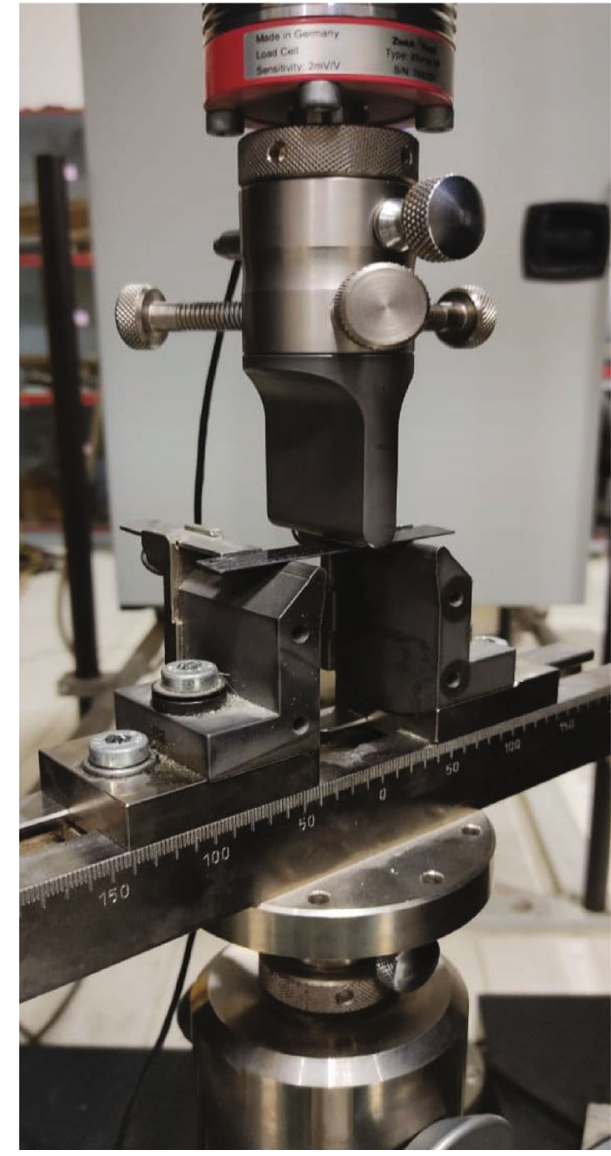

(b)

Figure 1: Continued. 


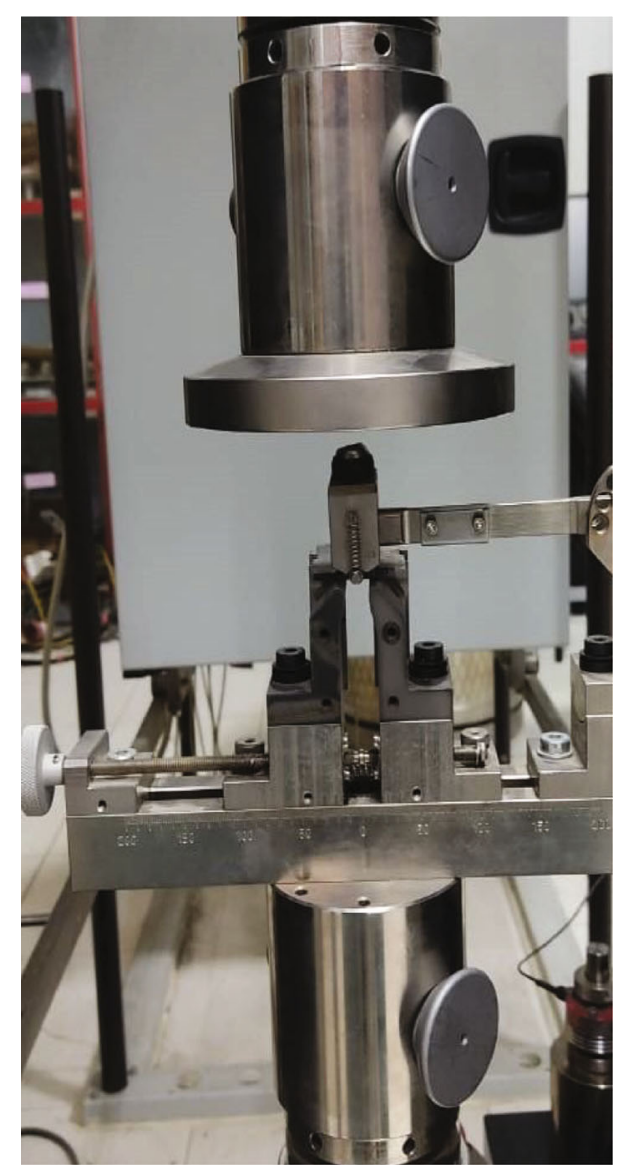

(c)

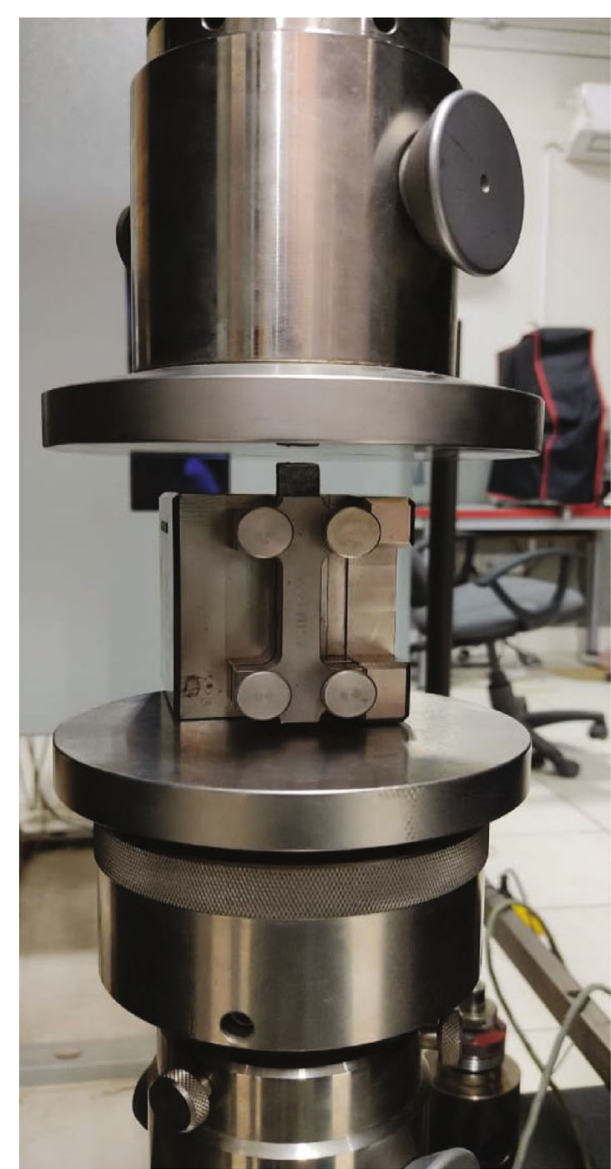

(d)

FIGURE 1: Continued. 


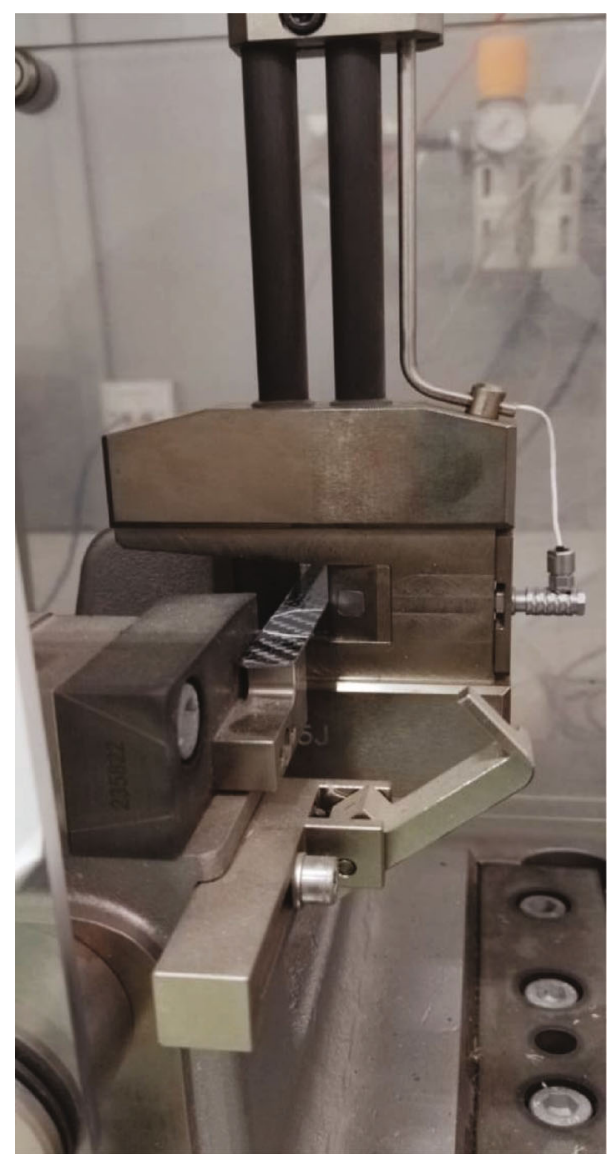

(e)

FIgURE 1: The composite specimen under (a) tensile, (b) flexural, (c) SBS, (d) compression, and (e) Charpy impact loading.

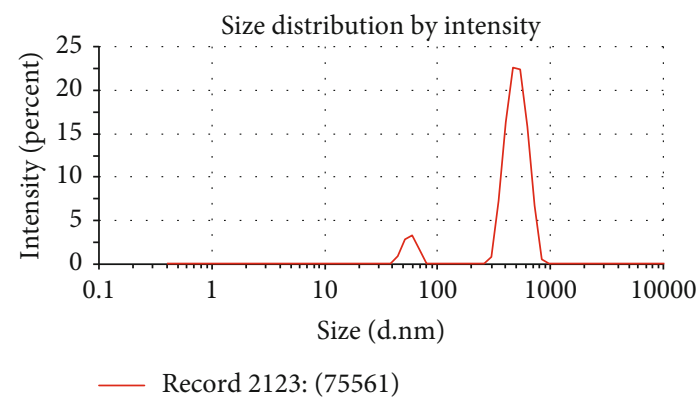

FIGURE 2: Zeta size distribution curve of PEEK particles.

challenging task. It mainly depends on the surface properties, chemical structure, concentration, curing temperature, and the curing rheokinetic at the set temperature [19]. The incorporation of preformed immiscible polymeric particles having well defined size seems to be an efficient substitute for phase-separating toughener agent. Preformed rubber and thermoplastic particles have also been commonly used for interlayer toughening of composites. With this technique, it is feasible to achieve a precise size distribution of particles in thermoset matrix [20-23]. Girodet et al. showed that incorporation of $30 \mathrm{phr}$ of PA6 preformed particles

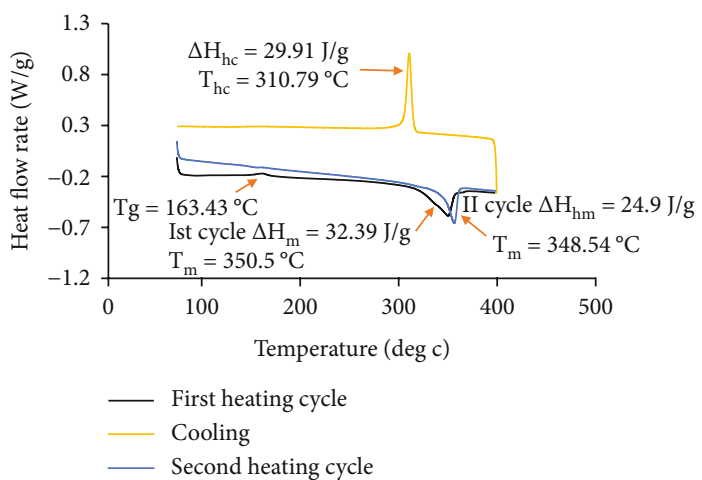

FIgURE 3: DSC of PEEK particles.

increases the critical stress intensity factor $\left(\mathrm{K}_{1 \mathrm{c}}\right)$ and critical strain energy release rate $\left(G_{1 c}\right)$ up to $37.9 \%$ and $90 \%$, respectively [22]. Kishi et al. explored that epoxy modified with $20 \mathrm{phr}$ preformed polyamide- 12 particles has 3 times more T-peel adhesive strength as compared to unmodified [23]. Chaudhary et al. stated that the 3\% $(w / w)$ incorporation of preformed polyethylene particles increases the high-speed impact properties and fracture energy of epoxy composite up to $21 \%$ and $44 \%$, respectively [24]. 


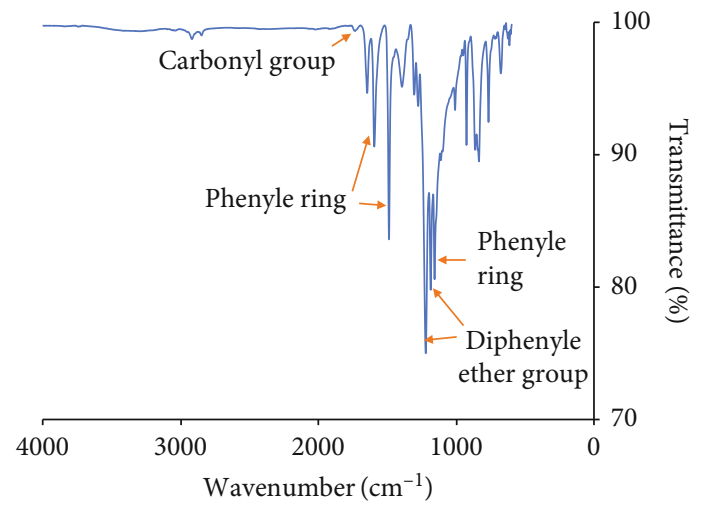

FIgUre 4: FTIR spectrum of PEEK particles.

Poly ether ether ketone (PEEK), a high molecular weight semicrystalline engineered thermoplastic, belongs to a family of poly aryl ether ketone. It has rigid aromatic backbone molecular structured chain that is linked together by ketone and ether functional groups. Because of this unique chemical structure, PEEK has outstanding mechanical properties, thermal stability, and tolerance to environmental factors. Furthermore, it is chemically stable to almost all organic and inorganic chemicals [25-29]. It is well known that weakly bonded filler debonds easily under stress, causing void formation and matrix shear yielding, allowing the composite to release more energy before its fracture [30, 31]. Owing to low surface energy and weak interfacial bonding with epoxy, PEEK has the potential to use as filler in carbon/epoxy composite. As far as our knowledge, no previous study exists that assess the effect of the incorporation of PEEK filler on the properties of carbon/epoxy composite.

The primary aim of this work was to examine the influence of micro-PEEK particles as tougher agent to enhance the physiomechanical properties of carbon/epoxy composite. Reinforcement dominated properties (tensile and flexural) and matrix dominated properties (short beam shear, compression, and impact) of the composites were extensively studied, with justified reasoning for the unusual behavior.

\section{Materials and Methods}

2.1. Materials. In this study, woven carbon fabric and a medium viscous epoxy resin were chosen as baseline materials. The $2 / 2$ twill weave carbon fabric was constructed with $3 \mathrm{~K}$ carbon filament of 33MSI, provided by BGF Industries, USA. It had a total areal density of $198 \mathrm{~g} / \mathrm{m}^{2}$ and a thread density of 5 threads per $\mathrm{cm}$ both in warp and weft direction. The bisphenol-A-based epoxy resin (Araldite LY 556) and cycloaliphatic polyamine-based curing agent (Aradur 22962) were supplied by Huntsman Advanced Materials, Switzerland. As per manufacturer recommendation, epoxy and curing agent were mixed in a stochiometric weight ratio $(100: 23)$ during the whole study. The PEEK particles (Vestakeep) were supplied by Evonik, Germany.

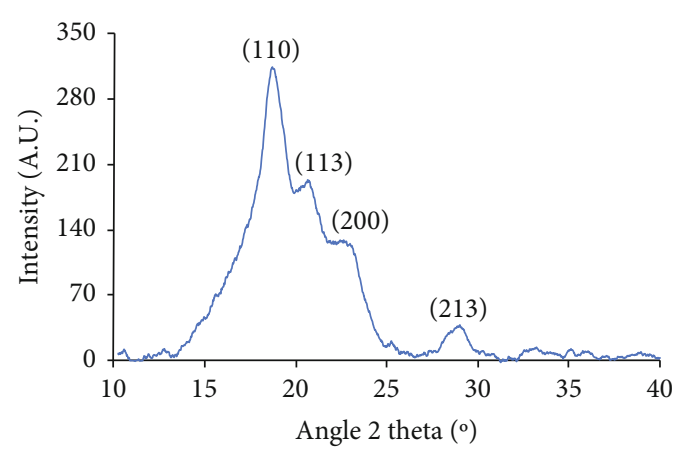

FIgURE 5: X-ray diffractogram of PEEK particles.

2.2. Composite Fabrication. Four layers of carbon fabric cut to a size of $(30.5 \mathrm{~cm} \times 30.5 \mathrm{~cm})$ and arranged in a lay-up of $[0 / 90]_{\mathrm{S}}$ were used as reinforcement. The content of PEEK particles corresponded to around $0 \%, 2 \%, 4 \%$, and $6 \%$ with respect to weight of epoxy matrix was mixed in epoxy resin with mechanical stirrer at 660 RPM for half an hour. After that, curing agent was mixed with epoxy in the specified ratio and stirred again for 10 minutes to achieve the consistent distribution of PEEK particles in the matrix. After stirring and mixing, the mixture was evenly distributed between the layers of carbon fabric by hand layup technique. Then, using compression molding technique, composite slabs were fabricated and cured for 40 minutes at 3.2 Bar pressure and $60^{\circ} \mathrm{C}$ temperature. Postcuring of composite was carried out at $150^{\circ} \mathrm{C}$ for 120 minutes in hot air oven.

2.3. Testing and Characterization. Using a Malvern Zetasizer (Nano S) that works on the dynamic light scattering principle, the $z$-average particle size and distribution of PEEK particles were calculated. Prior to test, the PEEK dispersion in ethanol was ultrasonicated for 10 minutes.

The crystallization and melting behavior of PEEK particles were investigated using differential scanning calorimeter (DSC 250), manufactured by TA Instruments. Sample weighing nearly $10 \mathrm{mg}$ was enclosed in Tzero hermetic aluminum pan, heated from $75^{\circ} \mathrm{C}$ to $400^{\circ} \mathrm{C}$, then cooled down from $400^{\circ} \mathrm{C}$ to $75^{\circ} \mathrm{C}$, and finally heated from $75^{\circ} \mathrm{C}$ to $400^{\circ} \mathrm{C}$. Every heating and cooling were performed with a temperature ramp of $10^{\circ} \mathrm{C} / \mathrm{min}$ and under nitrogen flow of $250 \mathrm{~mL} / \mathrm{min}$. The degree of crystallinity of PEEK was calculated using the following equation.

$$
\text { Degree of crystallinity, } \chi c=\frac{\Delta H_{m}}{\Delta H_{m}^{100 \%}} \times 100 \text {, }
$$

where $\Delta H_{m}$ and $\Delta H_{m}^{100 \%}$ are the melting enthalpy of used and $100 \%$ pure PEEK crystal that is $130 \mathrm{~J} / \mathrm{g}$ [32].

The Fourier-transform infrared (FTIR) spectrum of the PEEK particles was recorded using a Perkin-Elmer Spectrometer (Two Spectrum). The spectrum was collected in 20 scans over a range of $600-4000 \mathrm{~cm}^{-1}$.

$\mathrm{X}$-ray diffraction (XRD) analysis of PEEK particles was performed using Panalytical XRD (model X'Pert Pro) at $40 \mathrm{kV}$ and $30 \mathrm{~mA}$ with an increment of $0.01^{\circ}$. 
TABle 1: Physical properties of composite laminates.

\begin{tabular}{|c|c|c|c|c|c|c|}
\hline $\begin{array}{l}\text { Sample } \\
\text { code }\end{array}$ & $\begin{array}{c}\text { Filler } \\
\%\end{array}$ & $\begin{array}{l}\text { Theoretical density }(\mathrm{g} / \\
\left.\mathrm{cm}^{3}\right)\end{array}$ & $\begin{array}{l}\text { Experimental density (g/ } \\
\left.\mathrm{cm}^{3}\right)\end{array}$ & $\begin{array}{l}\text { Fiber volume fraction } \\
(\%)\end{array}$ & $\begin{array}{l}\text { Thickness } \\
(\mathrm{mm})\end{array}$ & $\begin{array}{c}\text { Void content } \\
(\%)\end{array}$ \\
\hline R0 & 0 & 1.43 & $1.43 \pm 0.02$ & $54 \pm 2$ & $0.90 \pm 0.1$ & $0.21 \pm 0.01$ \\
\hline $\mathrm{R} 2$ & 2 & 1.39 & $1.39 \pm 0.01$ & $45 \pm 1$ & $1.07 \pm 0.1$ & $0.22 \pm 0.01$ \\
\hline $\mathrm{R} 4$ & 4 & 1.39 & $1.38 \pm 0.005$ & $43 \pm 2$ & $1.10 \pm 0.1$ & $0.72 \pm 0.01$ \\
\hline R6 & 6 & 1.37 & $1.36 \pm 0.01$ & $41 \pm 2$ & $1.11 \pm 0.1$ & $0.73 \pm 0.01$ \\
\hline
\end{tabular}

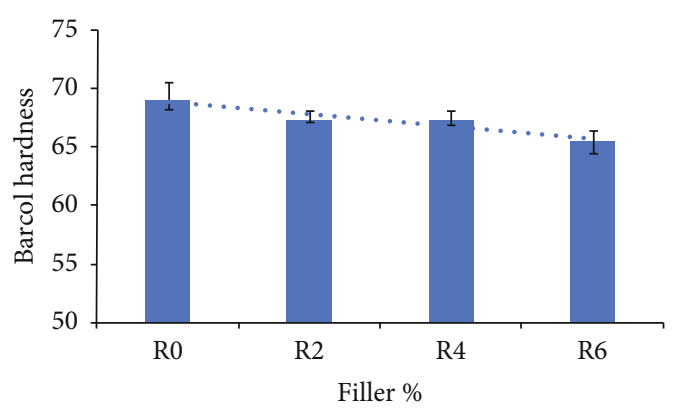

FIGURE 6: Barcol hardness of carbon/epoxy composite as a function of PEEK particles.

Fiber volume fraction $\left(V_{f}\right)$ of composite was calculated by ignition method according to Procedure G of ASTM D 3171-15. The actual density of the composite was measured using the Archimedes method in accordance with ASTM D 792 by determining the difference in weight between air and water.

The theoretical density was calculated using Equation (2). The ASTM 2734-16 standard was used to determine the void contents in composite using Equation (3).

Theoretical density, $P_{\text {theoretical }}=\frac{1}{\left[\left(W_{f} / \rho_{f}\right)+\left(W_{m} / \rho_{m}\right)+\left(W_{p} / \rho_{p}\right)\right]}$,

where $W_{f}, W_{m}$, and $W_{p}$ are the weight fraction of fiber, matrix, and filler, respectively. $P_{f}, P_{m}$, and $P_{p}$ are the density of fiber, matrix, and filler, respectively.

$$
\text { Void content }=\frac{\rho_{\text {theoretical }}-\rho_{\text {experimental }}}{\rho_{\text {theoretical }}} .
$$

The surface hardness was tested according to ASTM D 2583 using Zwick/Roell Barcol hardness tester. As the hardness of composite material is largely affected by the position of indentation, so twenty repetitions for hardness were performed on all over the composite palette to obtain optimum average result.

The tensile measurements were done on rectangular specimen of composite having a cut size of $200 \mathrm{~mm} \times 25$ $\mathrm{mm}$ and nonwoven glass-reinforced epoxy tabs $(25 \mathrm{~mm} \times 25 \mathrm{~mm})$ were adhered on both ends of the specimen. The experiments were carried out in compliance with the ASTM D 3039 standard, using a Zwick/Roell (Z100) uni- versal testing machine (UTM) fitted with a $100 \mathrm{kN}$ load cell and at a cross head speed of $2 \mathrm{~mm} / \mathrm{min}$. A Zwick/Roell mechanical contact type extensometer (MakroXtens) was used to monitor the longitudinal strain. For this test, fixture-to-fixture span length of $150 \mathrm{~mm}$ and a gauge length of $50 \mathrm{~mm}$ were used.

The 3-point bending process was used to report flexural properties in accordance with ASTM D 7264 over sample width of $13 \mathrm{~mm}$ by using Zwick/Roell UTM equipped with $1 \mathrm{kN}$ load cell. Flexural measurements were carried out at a cross head speed of $1 \mathrm{~mm} / \mathrm{min}$, with thickness to span and thickness to length ratios of $1: 32$ and $1: 40$, respectively.

The short beam strength was analyzed by using a Zwick/ Roell UTM with a width to thickness ratio of $2: 1$ and a span length to thickness ratio of $4: 1$ in compliance with ASTM D 2344. The load was applied at a $1 \mathrm{~mm} / \mathrm{min}$ cross head speed.

The compression properties were investigated according to ASTM D 695 having a cross head speed of $1.3 \mathrm{~mm} / \mathrm{min}$. The tests were done on rectangular specimen of composite having a cut size of $80 \mathrm{~mm} \times 13 \mathrm{~mm}$ and nonwoven glass reinforced epoxy tabs $(37 \mathrm{~mm} \times 37 \mathrm{~mm})$ were adhered on both ends of the specimen.

The impact properties of the fabricated composite having dimension of $80 \mathrm{~mm} \times 10 \mathrm{~mm}$ were investigated by means of Zwick/Roell instrumented Charpy impact tester (HIT 5.5), equipped with a hammer of 5 joule in compliance with ISO 179-2. Four replications were checked for each form of measurement, and average values were considered. The testing specimens under tensile, flexural, SBS, compression, and Charpy impact load are shown in Figure 1.

\section{Results and Discussion}

\subsection{Physical Characterization of PEEK Particles}

3.1.1. Particle Size Analysis. Particle size distribution curve obtained from zetasizer analysis reveals that PEEK particles are polydisperse in nature. Two peaks were observed which shows that $91.5 \%$ and $8.5 \%$ PEEK particles were in range of 501.9 d.nm to 56.41 d.nm, respectively, as shown in Figure 2. The $z$-average size of the particles was found to be 508 d.nm with a polydispersity index value of 0.663 .

3.1.2. Differential Scanning Calorimetry. Figure 3 shows the DSC heating, cooling, and reheating thermogram of the PEEK particles, and the characteristic data derived from the calorimetric curves are also shown in this Figure 3. In the case of first heating cycle, PEEK particles show a glass transition temperature at $166.43^{\circ} \mathrm{C}$ and an endothermic peak 


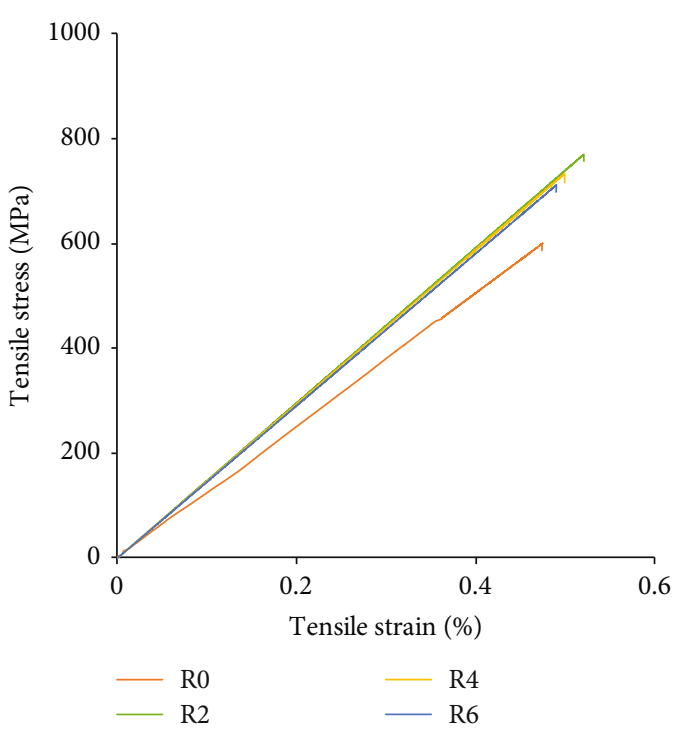

FIgURE 7: Normalized tensile stress/strain (average) curves of carbon/epoxy hybrid composite.

at $350.49^{\circ} \mathrm{C}$ which correlates to melting temperature of particles. An exothermic peak at $310.79^{\circ} \mathrm{C}$ was observed during the cooling cycle, which corresponds to hot crystallization. After removing the thermal stresses, the curve of second heating cycle shows no cold crystallization signals, and there is a minor decrease in melting temperature. It reveals that the particles may be composed of noncrystallizable material and thermally irritated. The melting enthalpy $\Delta H_{m}=$ $32.389 \mathrm{~J} / \mathrm{g}$ from the first cycle was used to calculate the crystallinity from Equation (1) which was found to be $24.91 \%$.

3.1.3. FTIR. The chemical composition of the PEEK powder was examined using FTIR spectroscopy, and the relevant spectrum is shown in Figure 4. The absorption peaks at $1160 \mathrm{~cm}^{-1}, 1491 \mathrm{~cm}^{-1}$, and $1597 \mathrm{~cm}^{-1}$ are associated to phenyl rings, and peaks at $1188 \mathrm{~cm}^{-1}$ and $1224 \mathrm{~cm}^{-1}$ are attributed to diphenylether group. A dimmer peak at $1735 \mathrm{~cm}^{-1}$ could be due to carbonyl group and is attributable to the thermally irritation of the PEEK particles $[33,34]$.

3.1.4. X-Ray Diffraction. Figure 5 presents the XRD results of the PEEK particles. The results demonstrate that PEEK is a semicrystalline polymer with distinct crystalline peaks in the 2 range of $20-30 \mathrm{o}$, matching to $(110,113,200$, and 213) planes [35].

\subsection{Physical Characterization of Composite}

3.2.1. Density, Void Content, and Fiber Volume Fraction. The density, fiber volume fraction, thickness, and void are listed in Table 1. Gradual decline in the density of the composites with increase in the percentage of the particles is the attribute of the bulk density of the PEEK particles, which is lower than the carbon fiber. The void content in the material has rising trend. This may be due to the fact that incorporation of fillers increases the viscosity of the resin which leads to increase in air traps and improper degasification of the resin [36]. As the resin became more viscous upon incorpo-

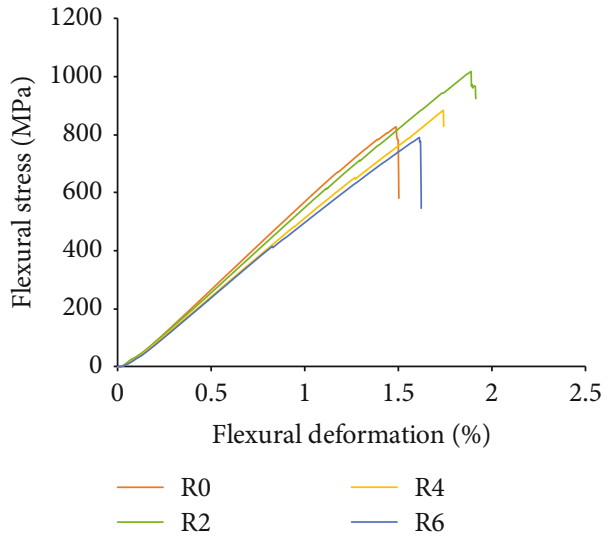

Figure 8: Normalized flexural behavior of carbon/epoxy hybrid composite.

ration of filler, the thickness of the composite increases which leads to downscale the fiber volume fraction of composite materials.

3.2.2. Barcol Hardness. The variations of Barcol hardness of composite materials with respect to concentration of PEEK particles are summarized in Figure 6. It shows that the hardness slightly decreases with the incorporation of the PEEK particles. This may be due to the low crystallinity of the PEEK particles that were mixed with the epoxy resin. As the concentration of PEEK particles increases, there are more particles present beneath the indenter of the hardness tester. These low crystalline thermoplastic fillers offer low resistance to the penetration of the indenter, resulting the hardness to be decreased.

\subsection{Mechanical Characterization of Composite}

3.3.1. Tensile Properties. As per measured result, the tensile strength and modulus of control sample (R0) having no filler were observed to be $599.27 \mathrm{MPa}$ and $126.65 \mathrm{GPa}$, respectively. The addition of $2 \%$ PEEK fillers has shown a positive influence of about $7 \%$ on the tensile strength of carbon/ epoxy composite. A possible reason for this improvement might be that the PEEK particles are larger in size than incoming crack tip, and therefore, they act as obstacles to crack propagation [37, 38]. Second toughing mechanism may be attributed to low surface energy of PEEK particles and its weakly bonding with epoxy resin. During load, the stress concentrations around the periphery of the PEEK particles debond it easily to promote void growth and/or shear banding in the matrix [39]. This leads to more dissipating of energy before failure. For R4 and R6, as the concentration was increased, the tensile strength was decreased by $3 \%$ and $10 \%$. This may be attributed to the high viscosity of resin that makes the degassing of matrix difficult, increase void content, and decrease in fiber volume fraction. The tensile modulus for R2, R4, and R6 was decreased by 3\%, $8 \%$, and $13 \%$, respectively. This loss in tensile modulus may be attributed to the loss of the stiffness of the epoxy matrix upon the addition of the thermoplastic filler in the matrix. The tensile test results were normalized to fiber volume fraction 


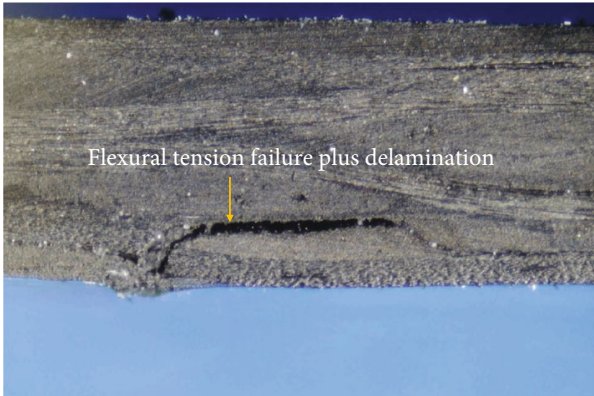

(a)

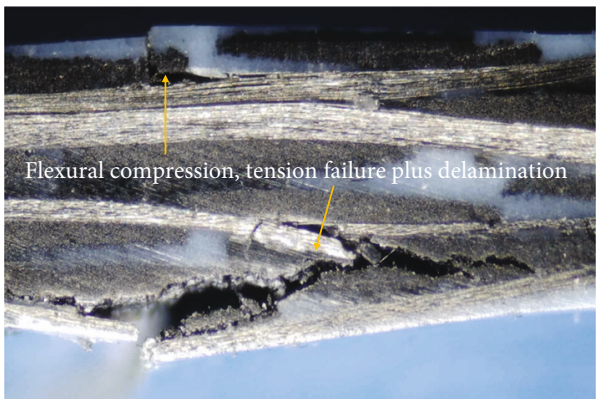

(b)

FIgure 9: Microscopic image of fracture surface after flexural test. (a) 0\% PEEK loading. (b) 4\% PEEK loading.

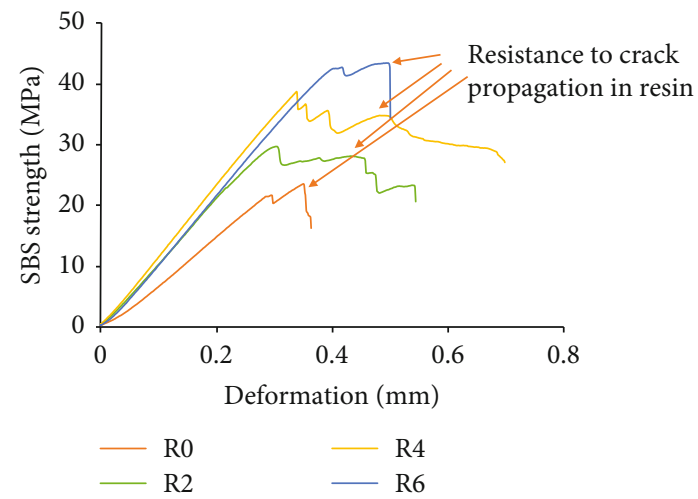

Figure 10: Normalized short-beam shear strength-deformation (average) curves of carbon/epoxy hybrid composite.

$\left(V_{f}=54 \%\right)$ to reduce the impact of deviations and improve comparison and shown in Figure 7. It depicts that composite containing 2\% PEEK particles was found to have greatest normalized tensile strength. It was increased by $28 \%$. For R4 and R6, the normalized tensile strength was increased by $22 \%$ and $19 \%$, respectively. For $2 \%, 4 \%$, and $6 \%$ incorporation of PEEK particles, the fiber volume fraction normalized tensile modulus was found to be increased nearly by $17 \%, 16 \%$, and $15 \%$, respectively. The reason for this nearly equal increment in normalized result of the tensile modulus is the properties and brittle nature of the carbon fiber that has a major part in the final properties of the composite as compared to that of matrix.

As seen in Figure 7, the stress-strain plots for the tensile test seem to show roughly linear behavior until the ultimate failure for each composite, which happens abruptly, and all these indicate the brittle nature of composite material.

3.3.2. Flexural Properties. According to as measured result, the flexural strength and modulus for R0 were found to be 826.27 $\mathrm{MPa}$ and $58.05 \mathrm{GPa}$, respectively. The increment in the flexural strength was observed only for the $\mathrm{R} 2$ composite while a trend of reduction in the flexural modulus was observed for each loading of PEEK particles. Upon the addition of $2 \%$ filler, flexural strength was increased by $3 \%$ and flexural modulus was decreased by $21 \%$ when comparing to R0. Further increase of the PEEK particles gradually reduces the value of both flexural strength and modulus. The flexural strength for R4 and R6 was found to be decreased by $15 \%$ and $28 \%$, respectively, while their flexural modulus was decreased by $28 \%$ and $34 \%$, respectively. Figure 8 demonstrates the flexural properties result normalized to fiber volume fraction to do down the effect of the variance. The normalized curves exhibit a linear deformation zone followed by abrupt failure which can be attributed to the brittle nature of both carbon fiber and epoxy resin. The normalized results show that specific flexural strength of $\mathrm{R} 2$ and $\mathrm{R} 4$ was increased by $23 \%$ and $7 \%$, respectively, while it is decreased by $5 \%$ for R6. A similar behavior as that of nonnormalized was also observed for fiber volume fraction normalized flexural modulus. It was found to be decreased by $5 \%, 10 \%$, and $13 \%$ with the addition of $2 \%, 4 \%$, and $6 \%$ of PEEK filler. This concurs the argument given in some literatures that the addition of thermoplastic filler in thermoset resin deteriorates the flexural properties by decreasing the rigidness of the composite material [40-42]. The locations of the flexural failure were primarily on the bottom surface of the tested specimen under loading nose which should be characterized as the tensile failure followed by some delamination in the last few plies of the composite. Besides these failures, R4 and R6 also exhibited flexural compressive failure too, as shown in Figure 9. A possible reason for this flexural compressive failure in high loaded PEEK particles composite might be that the addition of thermoset filler decreases the rigidness and Barcol hardness of the carbon/ epoxy composite. During flexural load, compressive failure begins by crushing the top plies at the compression side followed by yielding of bottom plies at tension side of the composite materials.

3.3.3. Short Beam Shear Properties. The SBS strength of sample R0 was observed to be $23.66 \mathrm{MPa}$. After linear deformation, R0 exhibited a small nonlinear deformation. The suddenly dropped of load indicating the brittle nature of the sample. For addition of $2 \%, 4 \%$, and $6 \%$ of PEEK particles, the as measured SBS strength was found to be increased by $4 \%, 31 \%$, and $39 \%$, respectively. Same linear increasing trends were observed for the fiber volume fraction normalized results as shown in Figure 10. As it is illustrated, the integration of PEEK particles in carbon-epoxy composite had a substantial effect on the SBS behavior. The specific short beam shear strength with respect to fiber volume fraction for R2, R4, and R6 was increased by $25 \%, 64 \%$, and $84 \%$, respectively. Further, the incorporation of the $2 \%, 4 \%$, and 


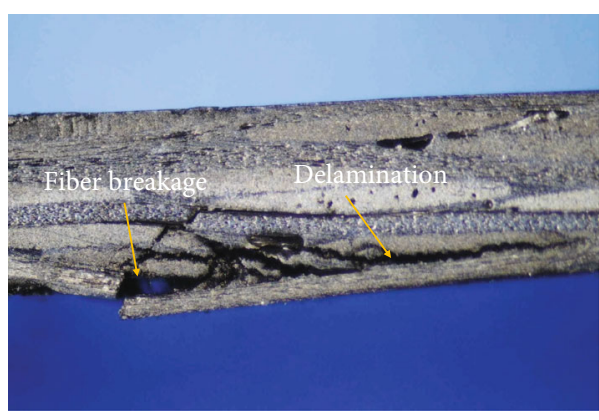

(a)

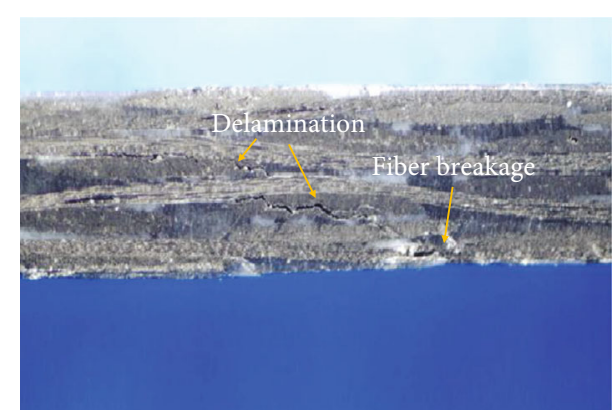

(b)

FIgURE 11: Microscopic image of fracture surface after short beam shear test. (a) 0\% PEEK loading. (b) 4\% PEEK loading.

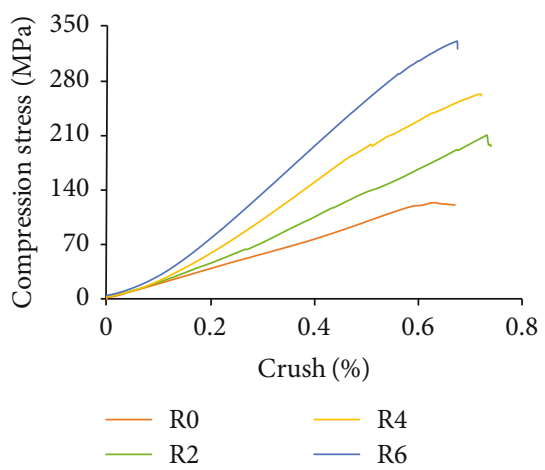

FIGURE 12: Normalized compression load-crush (average) curves of carbon/epoxy hybrid composite.

$6 \%$ of PEEK particles resulted in increasing of deformation at maximum in the elastic zone SBS strength curves and as well as it also increased the plastic deformation. Because the short beam shear strength is matrix-dominated property so the increment in the thickness of the adhesive layers between the plies of the carbon fabric may be one of the possible causes for the improvement of the SBS strength. In bulky layers of matrix, the filler offers more resistance to crack propagation as compared to the thin layer of same matrix. The distinct toughness mechanism is crack pinning, crack deflection, particle debonding, void growth, and matrix shear yielding $[10,43,44]$.

The failure modes of the tested sample were examined using a digital microscope and compared to the failure mode of the ASTM standards as shown in Figure 11. It was noted that chiefly delamination and flexure-tension type of failure mode were present in the tested sample.

3.3.4. Compression Properties. The control sample R0 exhibited a compressive strength and modulus of 124.2 MPa and 19.1 GPa. As per measured result, the compressive properties of the composite were found to be significantly increased with the use of the PEEK particles reinforced epoxy matrix. Upon incorporation of $2 \%, 4 \%$, and $6 \%$, the compressive strength was increased by $40.6 \%, 68.2 \%$, and $102.6 \%$, respectively, while the compressive modulus was increased by $7 \%$, $80.9 \%$, and $109.7 \%$, respectively. Figure 12 demonstrates the fiber volume normalized compression properties as compressive stress-crush percentage curves of carbon/epoxy

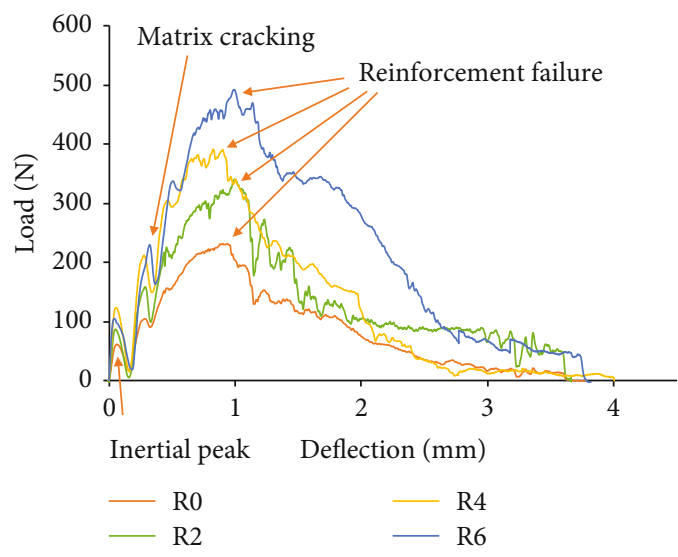

FIGURE 13: Normalized force-displacement (average) curves of carbon/epoxy composite obtained from instrumented Charpy impact tester.

composites with their matrices modified by PEEK particles. The specific compressive properties were also increased with the increase in the concentration of the PEEK particles. For $2 \%, 4 \%$, and $6 \%$ PEEK incorporation, the fiber volume fraction normalized compressive strength was increased by $68.7 \%, 111.2 \%$, and $166.9 \%$, respectively, and the specific compressive modulus was increased by $20.3 \%, 125.8 \%$, and $173.0 \%$, respectively.

The most prominent failure mode of continuous fiberreinforced composite material under compression loading is microbuckling of the fiber [45]. As the woven fabric that was used in this study reinforcement used has already a wavy configuration in the form of interlacing (up and down) of the filaments. They are readily prone to degrade under compression load. Addition of PEEK particles in the epoxy matrix may form microcomposites that resist the microbuckling of the fiber, leading to more energy absorption under compression load before failure.

3.3.5. Charpy Impact Properties. From the result, a noticeable increase in the maximum impact force $\left(F_{M}\right)$ was observed that the sample bear as a function of the incorporation of PEEK particles in epoxy matrix while the deflection at maximum force remains the same (approx. $0.9 \mathrm{~mm}$ ) for each. The control sample R0 exhibited maximum impact force of $232 \mathrm{~N}$. The maximum impact force of sample R2, R4, and 


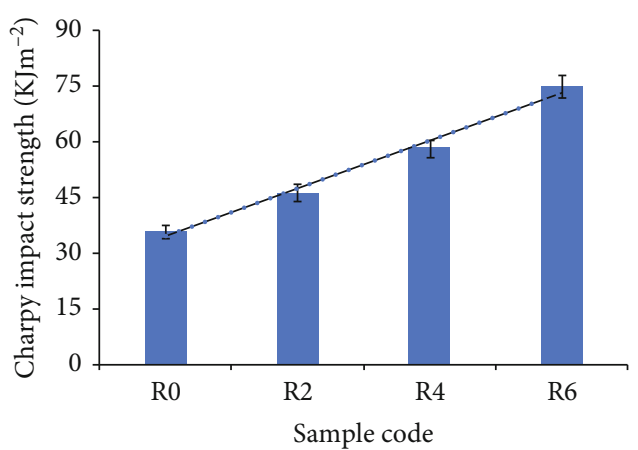

FIGURE 14: Normalized average Charpy impact strength of carbon/ epoxy hybrid composite as a function of PEEK percentage.

R6 was found to be increased by $23 \%, 34 \%$, and $62 \%$, respectively. The composite R4 shows a maximum inertial peak at $94 \mathrm{~N}$ which is $62 \%$ more than that of composite R0. The results of Charpy impact strength based on as measured value concedes a prominent increase in the Charpy impact strength with respect to the concentration of the PEEK particles. The control sample R0 exhibited an impact strength of $35.8 \mathrm{KJm}^{-2}$. The addition of $2 \%, 4 \%$, and $6 \%$ PEEK particles increase the impact strength to $38.5,46.4$, and $56.8 \mathrm{KJm}^{-2}$, respectively. The energy at maximum force of R0 based on as measured value was found to be $78.9 \mathrm{Nmm}$. The incorporation of $2 \%, 4 \%$, and $6 \%$ PEEK particles increased the energy at maximum force by $109 \%, 96 \%$, and $168 \%$, respectively. Figure 13 shows typical fiber volume normalized loaddeflection curves from the Charpy impact test. The fiber volume normalized $F_{M}$ for R2, R4, and R6 was increased by $47 \%, 69 \%$, and $113 \%$, respectively.

The normalized Charpy impact strength, as shown in Figure 14, for $2 \%, 4 \%$, and $6 \%$ PEEK loading was increased by $29 \%, 63 \%$, and $109 \%$, respectively. The normalized energy at the maximum force for R2, R4, and R6 was increased by $151 \%, 146 \%$, and $253 \%$, respectively, as shown in Figure 15. The increment in the Charpy impact force, strength, and energy at maximum force may be due to the existence of PEEK particles in the composite that provides excellent resistance to the crack progression in epoxy matrix. Moreover, the poor interfacial bonding between the PEEK particles and epoxy matrix leads to debonding and fiber full out damage mechanism under impact load which requires more energy as compared to that of fiber fracture mechanism $[46,47]$.

\section{Conclusion}

The systematic study of the carbon/epoxy composite illuminated that the incorporation of the PEEK particles decreases the density of composite because of the lower bulk density of PEEK particles as compared to that of carbon fiber. Despite low surface energy of PEEK, the improvements in SBS, compression, and Charpy impact properties may be an indication that PEEK particles effectively increase the matrix dominated properties in carbon/epoxy composite by providing different toughness mechanism including the debonding of PEEK particles, voids growth, crack pinning, and crack

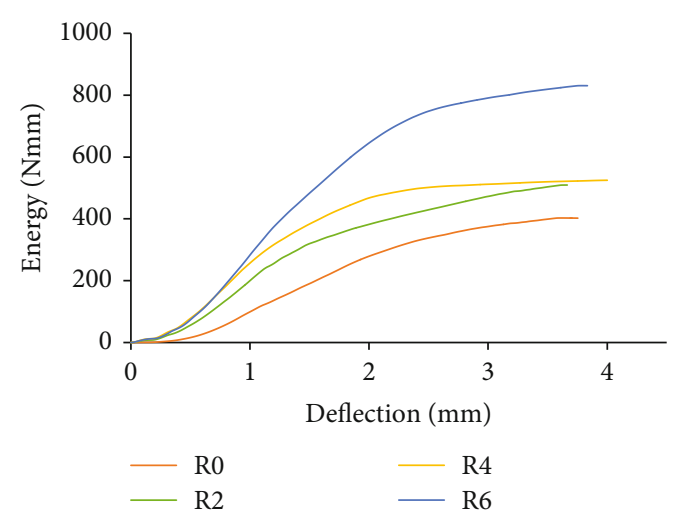

FIGURE 15: Normalized energy deflection (average) curves of carbon/epoxy hybrid composite.

deflection. As the percentage of the particles increased in composite, the surface Barcol hardness was also found to be decreased because of the low crystallinity $(24.91 \%)$ of PEEK particles. The rise in the viscosity with the addition of filler makes its degassing difficult. It increased the void content and thickness that ultimately led to decrease in the fiber volume fraction of the composite material. The normalized results with respect to fiber volume fraction illustrate that maximum improvement in the tensile strength (28\%), tensile modulus (17\%), and flexural strength (23\%) were found for $2 \%$ filler concentration. The flexural modulus had decreasing trend with particles incorporation in both, as measured and normalized results. The SBS, compression, and Charpy impact properties were found to have a linear positive trend. The normalized value of SBS was increased by $83.9 \%$ with $6 \%$ addition of PEEK particles. The normalized compression strength and modulus for $6 \%$ concentration were increased by $167 \%$ and $173 \%$, respectively. The normalized Charpy impact strength and energy were improved by $109 \%$ and $255.4 \%$, respectively.

Owing to viscoelastic nature of both epoxy and PEEK filler, the exposure of composite in hot and humid environmental circumstances from short to extended time can cause produce different reversible and permanent damages. Further studies are required to explore the effect of ageing in various environment on the failure strain, plastic deformation, and the impact properties of the carbon/epoxy hybrid composite.

\section{Data Availability}

Data will be made available on request.

\section{Conflicts of Interest}

The authors declare that they have no conflicts of interest.

\section{References}

[1] R. Hsissou, R. Seghiri, Z. Benzekri, M. Hilali, M. Rafik, and A. Elharfi, "Polymer composite materials: a comprehensive review," Composite Structures, vol. 262, 2021. 
[2] N. Hiremath, S. Young, H. Ghossein, D. Penumadu, U. Vaidya, and M. Theodore, "Low cost textile-grade carbonfiber epoxy composites for automotive and wind energy applications," Composites. Part B, Engineering, vol. 198, 2020.

[3] C. Soutis, "Fibre reinforced composites in aircraft construction," Progress in Aerospace Science, vol. 41, no. 2, pp. 143-151, 2005.

[4] M. Zamanian, M. Mortezaei, B. Salehnia, and J. E. Jam, "Fracture toughness of epoxy polymer modified with nanosilica particles: particle size effect," Engineering Fracture Mechanics, vol. 97, pp. 193-206, 2013.

[5] J. Lee and A. F. Yee, "Role of inherent matrix toughness on fracture of glass bead filled epoxies," Polymer, vol. 41, no. 23, pp. 8375-8385, 2000.

[6] M. M. Rehman, M. Zeeshan, K. Shaker, and Y. Nawab, "Effect of micro-crystalline cellulose particles on mechanical properties of alkaline treated jute fabric reinforced green epoxy composite," Cellulose, vol. 26, no. 17, pp. 9057-9069, 2019.

[7] S. R. Karnati, P. Agbo, and L. Zhang, "Applications of silica nanoparticles in glass/carbon fiber-reinforced epoxy nanocomposite," Composites Communications, vol. 17, pp. 32-41, 2020.

[8] G. Mittal, V. Dhand, K. Y. Rhee, S.-J. Park, and W. R. Lee, “A review on carbon nanotubes and graphene as fillers in reinforced polymer nanocomposites," Journal of Industrial and Engineering Chemistry, vol. 21, pp. 11-25, 2015.

[9] A. P. Siddhartha and A. D. Bhatt, "Mechanical and dry sliding wear characterization of epoxy- $\mathrm{TiO}_{2}$ particulate filled functionally graded composites materials using Taguchi design of experiment," Matererials \& Design, vol. 32, no. 2, pp. 615627, 2011.

[10] K. Shaker, Y. Nawab, and A. Saouab, "Influence of silica fillers on failure modes of glass/vinyl ester composites under different mechanical loadings," Engineering Fracture Mechanics, vol. 218, 2019.

[11] Z. Abbas, S. Shahid, Y. Nawab, K. Shaker, and M. Umair, "Effect of glass microspheres and fabric weave structure on mechanical performance of hemp/green epoxy composites," Polymer Composites, vol. 41, no. 11, pp. 4771-4787, 2020.

[12] S. A. Bello, J. O. Agunsoye, J. A. Adebisi, R. G. Adeyemo, and S. B. Hassan, "Optimization of tensile properties of epoxy aluminum particulate composites using regression models," Journal of King Saud University - Science, vol. 32, no. 1, pp. 402411, 2020.

[13] P. R. Pati and M. P. Satpathy, "Investigation on red brick dust filled epoxy composites using ant lion optimization approach," Polymer Composites, vol. 40, no. 10, pp. 3877-3885, 2019.

[14] P. R. Pati and A. Satapathy, "A study on processing, characterization and erosion wear response of Linz-Donawitz slag filled epoxy composites," Advances in Polymer Technology, vol. 34, no. 4, 2015.

[15] P. Ranjan Pati, "Characterization of glass-epoxy composites using red brick dust particles," Materials Today: Proceedings, vol. 18, pp. 3775-3779, 2019.

[16] P. Ranjan Pati and A. Satapathy, "Processing and characterization of glass-epoxy composites filled with Linz-donawitz (LD) slag," Universal Journal of Mechanical Engineering, vol. 3, no. 1, pp. 7-11, 2015.

[17] P. Ranjan Pati, M. Prasad Satpathy, and A. Satapathy, "Experimental investigation on Linz-Donawitz slag filled polypropylene composites using teaching-learning based optimization approach," Polymer Composites, vol. 39, no. 11, pp. 39443951, 2018.
[18] P. R. Pati and A. Satapathy, "Processing, characterization and erosion wear response of Linz-Donawitz (LD) slag filled polypropylene composites," Journal of Thermoplastic Composite Materials, vol. 29, no. 9, pp. 1282-1296, 2016.

[19] P. Huang, S. Zheng, J. Huang, Q. Guo, and W. Zhu, "Miscibility and mechanical properties of epoxy resin/polysulfone blends," Polymer, vol. 38, no. 22, pp. 5565-5571, 1997.

[20] D. Quan and A. Ivankovic, "Effect of core-shell rubber (CSR) nano-particles on mechanical properties and fracture toughness of an epoxy polymer," Polymer, vol. 66, pp. 16-28, 2015.

[21] G. Giannakopoulos, K. Masania, and A. C. Taylor, "Toughening of epoxy using core-shell particles," Journal of Materials Science, vol. 46, no. 2, pp. 327-338, 2011.

[22] C. Girodet, E. Espuche, H. Sautereau, B. Chabert, R. Ganga, and E. Valot, "Influence of the addition of thermoplastic preformed particles on the properties of an epoxy/anhydride network," Journal of Materials Science, vol. 31, no. 11, pp. 2997-3002, 1996.

[23] H. Kishi, K. Uesawa, S. Matsuda, and A. Murakami, "Adhesive strength and mechanisms of epoxy resins toughened with preformed thermoplastic polymer particles," Journal of Adhesion Science and Technology, vol. 19, no. 15, pp. 1277-1290, 2005.

[24] S. Chaudhary, S. Parthasarathy, V. Mangla, D. Kumar, and P. K. Roy, "Toughening of epoxy with preformed polyethylene thermoplastic filler," Polymer - Plastics Technology and Engineering, vol. 54, no. 9, pp. 907-915, 2015.

[25] M. Kyomoto, T. Moro, S. Yamane et al., "Smart PEEK modified by self-initiated surface graft polymerization for orthopedic bearings," Reconstructive Review, vol. 4, no. 3, pp. 36-45, 2014.

[26] L. Ouyang, Y. Zhao, G. Jin et al., "Influence of sulfur content on bone formation and antibacterial ability of sulfonated PEEK," Biomaterials, vol. 83, pp. 115-126, 2016.

[27] J. F. D. Montero, H. A. Tajiri, G. M. O. Barra et al., "Biofilm behavior on sulfonated poly(ether-ether-ketone) (sPEEK)," Materials Science and Engineering: C, vol. 70, Part 1, pp. 456-460, 2017.

[28] K. B. Sagomonyants, M. L. Jarman-Smith, J. N. Devine, M. S. Aronow, and G. A. Gronowicz, "The _in vitro_response of human osteoblasts to polyetheretherketone (PEEK) substrates compared to commercially pure titanium," Biomaterials, vol. 29, no. 11, pp. 1563-1572, 2008.

[29] S. M. Kurtz and J. N. Devine, "PEEK biomaterials in trauma, orthopedic, and spinal implants," Biomaterials, vol. 28, no. 32, pp. 4845-4869, 2007.

[30] H.-Y. Liu, G.-T. Wang, Y.-W. Mai, and Y. Zeng, "On fracture toughness of nano-particle modified epoxy," Composites. Part B, Engineering, vol. 42, no. 8, pp. 2170-2175, 2011.

[31] J. Lee, "Fracture of glass bead/epoxy composites: on micromechanical deformations," Polymer, vol. 41, no. 23, pp. 8363-8373, 2000.

[32] D. J. Blundell and B. N. Osborn, "The morphology of poly(aryl-ether-ether-ketone)," Polymer, vol. 24, no. 8, pp. 953958, 1983.

[33] L. Yang, Y. Ohki, N. Hirai, and S. Hanada, "Aging of poly(ether ether ketone) by heat and gamma rays - its degradation mechanism and effects on mechanical, dielectric and thermal properties," Polymer Degradation and Stability, vol. 142, pp. 117-128, 2017.

[34] H. Shi, J. Sinke, and R. Benedictus, "Surface modification of PEEK by UV irradiation for direct co-curing with carbon fibre reinforced epoxy prepregs," International Journal of Adhesion and Adhesives, vol. 73, pp. 51-57, 2017. 
[35] G. Zhang, S. Leparoux, H. Liao, and C. Coddet, "Microwave sintering of poly-ether-ether-ketone (PEEK) based coatings deposited on metallic substrate," Scripta Materialia, vol. 55, no. 7, pp. 621-624, 2006.

[36] H. Zhu, B. Wu, D. Li, D. Zhang, and Y. Chen, "Influence of voids on the tensile performance of carbon/epoxy fabric laminates," Journal of Materials Science and Technology, vol. 27, no. 1, pp. 69-73, 2011.

[37] S.-Y. Fu, X.-Q. Feng, B. Lauke, and Y.-W. Mai, "Effects of particle size, particle/matrix interface adhesion and particle loading on mechanical properties of particulate-polymer composites," Composites. Part B, Engineering, vol. 39, no. 6, pp. 933-961, 2008.

[38] D. J. Bull, A. E. Scott, S. M. Spearing, and I. Sinclair, "The influence of toughening-particles in CFRPs on low velocity impact damage resistance performance," Composites. Part A, Applied Science and Manufacturing, vol. 58, pp. 47-55, 2014.

[39] H. Ma, M. A. Aravand, and B. G. Falzon, "Synergistic enhancement of fracture toughness in multiphase epoxy matrices modified by thermoplastic and carbon nanotubes," Composites Science and Technology, vol. 201, 2021.

[40] B. Francis, V. Lakshmana Rao, R. Ramaswamy, S. Jose, S. Thomas, and K. V. S. N. Raju, "Morphology, viscoelastic properties, and mechanical behavior of epoxy resin modified with hydroxyl-terminated poly(ether ether ketone) oligomer with pendent tert-butyl groups," Polymer Engineering \& Science, vol. 45, no. 12, pp. 1645-1654, 2005.

[41] R. Ollier, A. Stocchi, E. Rodriguez, and V. Alvarez, "Effect of thermoplastic incorporation on the performance of thermosetting matrix," Materials Sciences and Applications, vol. 3, no. 7, pp. 442-447, 2012.

[42] B. Francis, S. Thomas, J. Jose, R. Ramaswamy, and V. Lakshmana Rao, "Hydroxyl terminated poly(ether ether ketone) with pendent methyl group toughened epoxy resin: miscibility, morphology and mechanical properties," Polymer, vol. 46, no. 26, pp. 12372-12385, 2005.

[43] M. Alsaadi, A. A. Ugla, and A. Erklig, "A comparative study on the interlaminar shear strength of carbon, glass, and Kevlar fabric/epoxy laminates filled with SiC particles," Journal of Composite Materials, vol. 51, no. 20, pp. 2835-2844, 2017.

[44] M. Bulut, M. Alsaadi, and A. Erkliğ, "A comparative study on the interlaminar shear strength of S-glass/epoxy composites containing borax, perlite and sewage sludge ash particles," Materials Research Express, vol. 6, no. 9, 2019.

[45] S. Kyriakides, R. Arseculeratne, E. J. Perry, and K. M. Liechti, "On the compressive failure of fiber reinforced composites," International Journal of Solids and Structures, vol. 32, no. 67, pp. 689-738, 1995.

[46] G. Mehta, L. T. Drzal, A. K. Mohanty, and M. Misra, "Effect of fiber surface treatment on the properties of biocomposites from nonwoven industrial hemp fiber mats and unsaturated polyester resin," Journal of Applied Polymer Science, vol. 99, no. 3, pp. 1055-1068, 2006.

[47] B. K. Goriparthi, K. N. S. Suman, and N. Mohan Rao, "Effect of fiber surface treatments on mechanical and abrasive wear performance of polylactide/jute composites," Composites Part A: Applied Science and Manufacturing, vol. 43, no. 10, pp. 1800-1808, 2012. 